\title{
Infección congénita por virus Herpes simplex
}

\author{
Regina Schultz A. ${ }^{1}$; Carmen Larrañaga L. ${ }^{1,2}$; Elba Wu H. ${ }^{2}$; Mónjca Suárez G. ${ }^{1}$ \\ Prenatal herpes simplex virus infection
}

Five cases of probably intrauterine herpesvirus infection are discussed. Four of them had clirical evidence of neonatal herpes, which was disemina1ed in two patients, localized to skin in one case and with SNC compromised in other Natal or post natal infections were not considered to be possible in these infants due to the presence of simptoms in the first 24 hours of rife, which made ascending transcervical or transplecental the most probable route for viral transmission. All cases were treatec with a ten davs course of intravenous acyclovir during 10 davs. There of thern had satisfactory evolution and the other two died at 9 days and at 2 months of life.

[Key words: herpes simplex, infection, prenatal.]

El herpes neonatal es una enfermedad grave cuya principal fuente de infección es la transmisión de la madre al hijo, que puede producirse en el periodo prenatal, natal o postnatal ${ }^{1,2}$.

1. Deparlamento de Microbiología y Parasitoiogia, Facultad de Medicina, División Cjencjas Médicas Norte, Universidad de Chile.

2. Servicio de Pediatría, Hospital San Juan de Dios. Financiado por Proyecto $0135 / 88$, FondecytConicyt.
La transmisión natal es la forma más frecuente y ocurre en el paso por el canal genital materno infectado. La transmisión prenatal es menos frecuente, pero puede causar aborto, malfomaciones, parto prematuro e infección congénita. Esta forma se está observando con mayor freciencia en el último tiempo y se postula que el mecanismo a travês del cual se infecta el feto podría ser transplacentario o por vía ascendente, desde genitales externos hacia el üterol, ${ }^{1}$. En 
las primoinfecciones es lógico pensar que ellas se originan por via transplacentaria debido a la viremia existente. En las recurrencias el mecanismo es menos claro y se postulan dos hipó. tesis: infección ascendente, o bien cierto grado de viremia asociado a algunos casos de recurencias. Ambas hipótesis requieren estudios que aporten evidencias concluyentes. Es por estas razones que cuando se ha producido una infección intrauterina, la cesárea no previene el herpes neonatal, pudiendo nacer el niño con manifestaciones clinicas o desarrollarlas en las primeras 24 horas de vidas. En cambio, en las embarazadas con antecedentes herpéticos el control clínico y virológico durante el período final del embarazo es capaz de prevenir la infección en el parto, si se hace cesárea en caso de aislarse virus herpes simplex VH los días previos al nacimiento.

El objetivo de este trabajo es mostrar evidencia que respalda la existencia de infección intra-

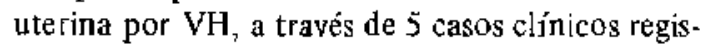
trados en los últimos dos años.

\section{Pacientes y Métodos}

En todos los casos que se describen a continuación se realizaron técnicas para aislamiento viral y estudio serológico de las madres y los recièn nacidos. Cuando fue posible aislar virus, éste fue tipificado. Para el aisla. miento vìral se utilizó el cultivo de células VERO : las niuestras tomadas fueron transportadas al laboratorio en medio de transporte a $4^{\circ} \mathrm{C}$; allí fueron procesadas $y$ cada muestra se inoculó en monocapa de células VERO, en duplicado, y fueron observadas con microscopia óptica por 7 días. El estudio serológico de madres e hijos se realizó con técnica de tijación del complemento y la tipificación viral mediante anticuerpos monoclonales fluorescentes (inmunofluorescencja indirecta (IFI)).

1. Recién nacido de término, sexo masculino, peso al nacer de 3.850 g y Apgar 9. Producto del tercer embarazo, madre de 28 años, antecedentes de herpes labial en ambos padres. Primoinfección genital herpética de la madre en el segundo mes de gestación, que recurrió 3 veces durante el cmbajazo, la última vez en et tercet trimestre. A las 39 semanas de edad gestacional se indicó cesárea por sals antecedentes. Las membranas ovulares estaban intactas.

El recién nacido tenia dos lesiones micropapulosas en la región perianal y dos días más tarde se agregaron lesiones microvesiculosas en pliegues, que se extendieton al cuero cabelludo, de las cuales no se consiguió aislar VH. Sin embargo, debido al típo de lesiones y a los antecedentes maternos, se consideró que se trataba de herpes neoratal localizado y se le indicó aciciovit endovenoso $10 \mathrm{mg} \cdot \mathrm{kg} \cdot$ dosis cada 8 horas durante 10 días. Evolucionó bien y con buen desarrollo psicomotor hasta completarse dos meses de obser. vación.
2. Recién nacido de término, adecuado para la edad gestacional, sexo masculino, pesó $3.760 \mathrm{~g}$ al nacer. Madre primigesta de 20 años de edad, sin antecedentes herpéticos. Padre con antecedentes de herpes labial. A las 39 semanas de gestación la madre sufrió primoinfección genital herpética, confirmada por aislamjento viral y seroconversión con títulos de fijación del complemento de 1:16 y 1:128. Ties dias después ocurrió el parto via vaginal. El recién nacido suftió astíixia grúve al nacer, de la que sólo se recuperó parcialmente. A los 15 minutos de vida presentó crisis espástica con rigidez de descerebración. En el examen físico habían lesiones vesiculosas del cuello, muñeca y coxis. Con los diagnósticos de encefalitis herpética y cutánea se trató con aciclovir endovenoso $10 \mathrm{mg} \cdot \mathrm{kg} \cdot$ dosis cada 8 horas desde las 12 horas de vida, pero evolucionó desfavorablemente y falleció a los 9 días de vida a causa de su encefalopatía. Los ajslamientos virales y la serología en el nito no dieron resultados positivos.

3. Recién nacido de término, adecuado para la edad gestacional, sexo masculino, pesó al nacer $3.660 \mathrm{~g}$. Tuvo asfixia neonatal que fue tápidamente tecuperada. Madre primigesta de 17 años de edad, sin antecedentes herpéticos en ella ni su pareja. Parto vaginal a las 38 semanas de gestación, dos horas después se observan, en el recién nacido, microvesículas del tronto y los pliegues que rápidamente se generalizaron agregándose hepatomegalia y fiebre, irtitabilidad e hipotonja generalizada. El diagnóstico de herpes neonatal diseminado se demostró por identificación de VH-2 en las lesiones cutáneas mediante reacciones de inmunofluorescencia indirecta (IFT). Fue tratado desde las $16 \mathrm{~h}$ de rida con aciclovir oral $15 \mathrm{mg} \cdot \mathrm{kg} \cdot$ dosis cada 8 horas pot no disponer de otra forma del medicamento y por vía endovenosa desde la: $48 \mathrm{~h}$. A las $72 \mathrm{~h}$ de vida, debido a hiperbilirrubinemia, se instaló brevemente en fototerapia, que se suspendió porque se exacerbaron las lesiones. Completó 10 días de tratamiento antivital, evolucionando bien. Al tercer mes de vida parecía sano y su desarrollo psicomotor era normal.

4. Madre primigerta de 22 años, sin antecedentes herpéticos personales. Antecedentes de herpes labial y genital de su pareja. Entre las 33 y 34 semanas de gestación ingresó al servicio de ginecología y obstetricia por liebre y lesión exudativa amigdaliana que no mejoró con penicilina, a la que se agregaron confusión y agjtatción psicomotora. El diagnóstico de herpes simplex diseminado se comprobó con aislamiento viral para VH-2 en orina y secreción faringea. Fue tratada con aciclovir endovenoso por 10 días $y$ a las 36 semanas de gestación se realizó cesárea por suftimiento fetal agudo. El recién nacido, de sexo temenino, pesó $2.660 \mathrm{~g}$, Apgar 9 (1 y $5 \mathrm{~min}$ ), membranas ovulares intactus $\mathrm{y}$ examen físico nomal, a perar de lo cual se trató también con aciclovir por vía endovenosa en forma prof $j$ láctica, $15 \mathrm{mg} \cdot \mathrm{kg} \cdot$ dosis cada 8 horas, evolucionando sin problemas. Las muestras para asslamiento y serología viral de esta niña también dieron resultados negatjvos.

5. Recién nacido pretếrmino, adecuado pasa la edad gestacional (36 semanas), sexo femenino, peso de nacimiento de $2.200 \mathrm{~g}$, Apgar de 7 y 9 . Madre multipara de 3 hijos sanos, antecedentes de infección herpética cutánea dutante el primer trimestre del embarazo. Parto vaginal a las 38 semanas de gestación, cefáli- 
ca, líqujdo anniótico con meconio, rotura de membranas durante el parto. La recién nacida presentaba signos de inmadurez y comenzó en la primera hora de vida con signos de dificultad respiratoria, requiriendo oxigenoterapia y en el primer día hiperbilìrubinemia (bilirrubinemia $10,5 \mathrm{mg} \%$ ) en coincidencia con incompatibilidad de grupo clásico O-A, por lo que se indicó fototerapia. A las 24 horas de vida se pesquisaron lesiones cutáneas de extremidades y cuero cabelludo, letargo, persistencia de la dificultad respiratoria, ictericià y dilatación moderada de todo el sistema ventricular encefálico. Se comprobó infección congénita por virus herpes demostrándola por aislamiento de $\mathrm{VH}-2$ del cérvix materno y de las lesiones cutáneas de la niña. Se fornularon los diagnósticos de infección congénita por virus herpes y meningoencefalitis herpétjca. Recibió tratamiento con aciclovit $10 \mathrm{mg} \cdot \mathbf{k g}$-dosis cada $8 \mathrm{~h}$ ev. y evolucionó estable desde el punto de vista geneIal, regresando las lesiones cutáneas; sin embargo, el daño neurológico persistió, confirmándose éste con tomograf́a axial computarizada cerebtal. A los 14 días de vida se le instaló válvula ventriculoperitoneal. Falleçó a los 2 meses de vida, después de ser trasladada a otro hospital, debido a secuelas neutológicas severas.

\section{Discusiốn}

En cuatro de estos casos existía algún antece. dente de infección herpética materna $y$ en los cuatro en que habia evidencia clínica de herpes neonatal ésta se registró en el parto o dentro de las 24 horas siguientes, hecho que permite asegurar que se trataba de inferciones intrauterinas, ya que, de acuerdo al periodo de incubación de estos virus ( 2 a 12 días), se descartaria la posibilidad de que ellas hubiesen sucedido en el momento del parto. Más aún, en uno de los casos la madre sufrió síntomas recurrentes de enfermedad herpética durante la gestación y el parto, razón por la cual se le practicó una cesárea con membranas intactas; esto permite postular que la infección fue vía transcervical o transplacentaria ${ }^{1}$.

Las infecciones neonatales por virus herpes $\mathrm{y}$ sus distintas formas de presentación han aumentado en los años más recientes. Este incremento ha sido consecuencia del aumento experimentado por el herpes genital, que representa la primera causa de ulceración genital en los paj. ses desarrollados ${ }^{8}$. Hasta ahora la mayoría de los casos de herpes neonatal informados en nuestro pais correspondian a infecciones adquiridas en el momento del parto, lo que podria prevenirse mediante cesárea en caso de detectarse la infec. ción genital en este periodo. En las infecciones intrauterinas, en cambio, la intervención no tendría ningún efecto preventivo. Las infecciones intrauterinas, ya transplacentarias o transcervicales, han aumentado considerablemente ${ }^{1,4}$, lamentablemente no siempre es posible confirmarlas virológicamente, como ocurió en nuestros pa. cientes, los que, sin embargo, mostraban evidencia clínica y epidemiológica muy contundente de infección herpética. Aun cuando no se cuenta con medidas de prevención, existe la posibilidad de tratamiento efectivo, razón por la cual es importante considerar las diferentes formas de transmisión de la infección herpética de la madre al hijo con el fin de diagnosticar precozmente y tratar de manera adecuada y oportuna al recién nacido.

En las primoinfecciones maternas, durante el tercer trimestre del embarazo, debería hacerse tratamiento antiviral de la madre, con el fin de prevenir la diseminación de la infección en ella misma y la infección del feto". El caso 4 describe una primoinfección hetpética materna durante el tercer trimestre del embarazo, tratada con aciclovir. La niña al nacer no presentó evi. dencias clínjcas ni serológicas de infección, si bien no se estudiaron en ella anticuerpos de tipo IgM. Si ocurió infección transplacentaria, lo que es muy probable, ya que la madre recibió aci. clovir al décimo dia de enfermedad, la terapia antiviral in utero pudo haber impedido el desarrollo de daño en el feto. Algunos clínicos son partidarios del tratamiento profiláctico de todo recién nacido expuesto a infección herpética, dada la escasa morbilidad asociada con el tratamiento y los buenos resultados obtenidos con él.

Los anticuerpos tipo IgM detectados en recién nacidos en los que se sospecha herpes neonatal son difíciles de interpretar por la alta frecuencia de falsos positivos y negativos que resulta de la técnica serológica empleada. Por otra parte, la presencia de anticuerpos tipo $\mathbf{l g G}$ en el neonato no indica infección del mismo, ya que pueden corresponder a anticuerpos maternos. La ausencja de estos anticuerpos, medidos por fijación del complemento en el recién nacido, no descarta la infección neonatal, ya que en ciertos casos de primoinfecciones maternas, con enfer. medad severa durante el tercer trimestre del embarazo, la seroconversión en la madre puede ser tardía o no ocurrir, como puede observarse en algunos casos con síntomas recurrentes.

Cuando se sospecha herpes neonatal se debe hacer tratamiento con aciclovir en dosis de 10 a $15 \mathrm{mg} \cdot \mathrm{kg}$.día. La droga tiene escasos efectos 
tóxicos y usada oportunamente disminuye la mortalidad causada por la enfermedad de 70 a $20 \%$. Este hecho adquiere mayor relevancia por cuanto el aislamiento del virus herpes desde el liquido cefalorraquídeo tiene apenas $5 \%$ de rendimiento y la serología sólo permite confirmar el diagnóstico cuando se produce seroconversión, hecho que demora aproximadamente 15 días, cambio que no ocurre en todos los casos.

\section{Resumen}

Se presentan 5 casos de probable infección herpética intrauterina; en 4 de el]os se comprobó clinicamente la presencia de herpes neonatal, observándose un caso localizado a piel, dos casos de herpes diseminado $y$ un herpes neonatal con compromiso del sistema nervioso central. En los cuatro casos enfermos se descartó la posibilidad de infección postnatal o durante el parto, puesto que presentaron signos o sintomas de la enfermedad antes de transcurit 24 horas de vida. En ellos se plantea la posibilidad de infección transcervical o transplacentaria. Todos los recién nacidos fueron tratados con aciclovir endovenoso por 10 días, evolucionando bien 3 de ellos; los otros 2 fallecen; uno a los 9 días y el otro a los 2 meses de vida por encefa. litis y secuelas neurológicas severas, respectivamente.

(Palabras clave: herpes simplex, infección prenatal.)

\section{Referencias}

1. Hutto, C.: Arim, A.; Jocobo. R. et al: Intrautetine herpes simplex virus infection. Pediatr 1987; 110: 97-101.

2. Freij, B.; Serer. J.; Frey, MD. et al.: Herpes virus infection in pregnancy: risk to Embryo, Fetus and Neonate. Clin Perinatol 1988; $15: 203-231$.

3. Prober, Ch.; Sullender, w,; Yasukawa, L. et al.: Low risk of herpes simplex virus infection in neonates exposed to the virus at the time of vaginal đelivery to mothers with recurrent genital herpes simplex yirus infection. New Engl $\mathrm{J}$ Med 1987; 316: 240-244.

4. Robb. J.; Benirschke, $K .:$ Mannino, $F$ et al.; Intrauterine iatent herpes simplex virus infection. Hum Patlrol 1986; 17: 1210-1217.

5. Whithley, R.; Corcy, L.; Arvin, A. et al.. Changing presentation herpes simplex virus infection in neonates. J Infect Dis 1988: 158: 109-1 16.

6. Binkin, N.; Koplan, J.; Cotes, W.: Preventing Neonatal Herpes. JAMA 1984; $251: 2816-2821$.

7. Prober, Ch,; Hensieigh, P.; Boucher, F. et. al: Use of routine yiral cultures at delivery to identify neonates exposed to herpes simplex virus. New Engl J Med 1988; 318: 887-891.

8. Corey, L.: Hoimes, K.: Genital herpes simplex virus infections: current concepts in diagnosis: thesapy and prevention. Ann intern Med 1983; 98: 973-983.

Esta publicación está disponible en copias de microfilms de 16 y $35 \mathrm{~mm}$ y microfichas de $105 \mathrm{~mm}$, las que pueden solicitarse a:

University Microfilms International

300 North Zeeb Road

Ann Arbor, Michigan 48106, USA.

This joumal is also avajlable in $16 \mathrm{~mm}$ microfilm, $35 \mathrm{~mm}$ microfilm and $105 \mathrm{~mm}$ microfilm copies through University Microfilms International, 300 North Zeeb Road, Ann Arbor, Michigan 48106, USA. 